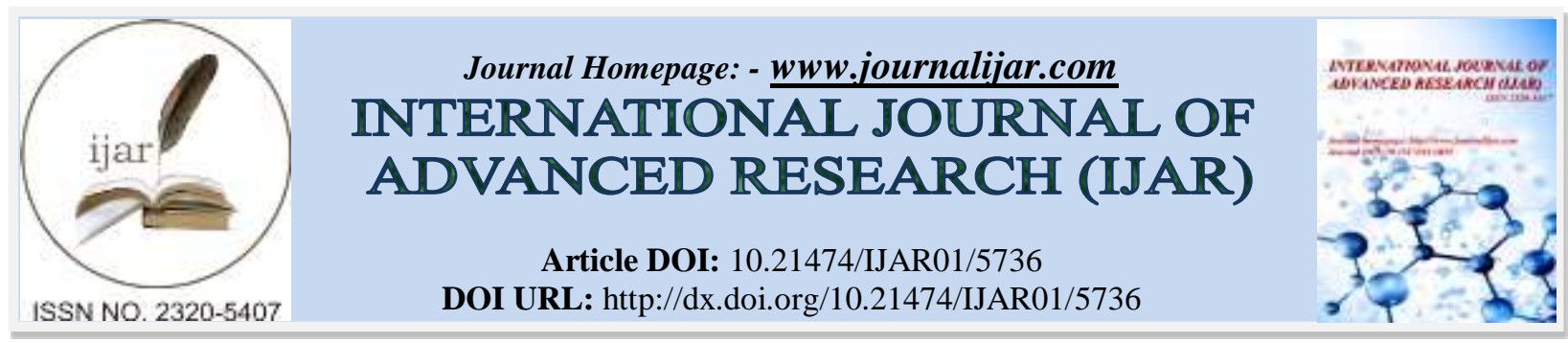

RESEARCH ARTICLE

\title{
MAKE A MULTI-CRITERIONS DECISION BY USING THE HIERARCHICAL ANALYTIC PROCESS FOR EVALUATING OF SELECTION AN OPTIMAL LOCATION.
}

\section{Dr. Omar Mohammed Naseer Alashari and Ali Mohammed Hasan Almobarqaa.}

\section{Manuscript Info}

Manuscript History

Received: 01 September 2017

Final Accepted: 03 October 2017

Published: November 2017

\section{Keywords:-}

Analytic Hierarchy Process (AHP), Make A Multi-Criterions Decision, The use matrix algebra.

\begin{abstract}
The aimed of study to achieve a limited number of decisions by highlighting upon one of its represented models in the stylistics' hierarchical analysis and applied Analytic Hierarchy Process (AHP) in assessing the choosing of location is selected among several locations and the validity of the location selection adopted by The Organization National Investment in Iraq for establishing the largest city residential and completely services in borders of Baghdad capital of Iraq. Especially, the location which is indicated by the organization and has been under supervision by The Organization National Investment, which it has undergone this study for several criteria who is put by decision makers.
\end{abstract}

Copy Right, IJAR, 2017,. All rights reserved.

\section{Introduction:-}

This study highlights on the decision-making model multi-criteria determination, hence alternatives will be carefully studied. With assist of experts, we will develop the appropriate criteria that will contribute to the selection of alternatives from different alternatives and putting the suitable weights for comparison by using binary matrices throughout using by Analytic Hierarchy Process (AHP), the assessment of the location selection approved by the National Investment Organization in Iraq to establish an integrated residential city with more than one hundred thousand housing units with all related services Out.

If we supposed that the dependence on experience and intuition for investment of funds close to cost of ten billion US dollars without relying upon the scientific methods which are contributed in the fortification and decisiveness of the decision from weakness and flaw, it may be a dangerous adventure that could lead to the failure of the project or reduce the feasibility. The project has contributed to the treatment of one of the biggest crises experienced by the Iraqi citizen, namely the housing crisis. In addition, there is a many objection for the establishment of this project, which is made the managers of the project in front the major challenges, especially as Iraq undergone the economic and security crisis, it does not allow any an error or failure like these projects.

Therefore, we have prepared this study for using the theory is an Analytic Hierarchy Process of Professor Thomas L. Saaty, for evaluating the selection of alternative based upon the several criteria, which its put previously by experts and specialists through a questionnaire had been distributed to them for revealing the weights criteria which are put before. It is an evaluation of study within strategic dimensions to benefit from in:

First: Evaluating the selection of The Organization National Investment to a location which is chosen by (ONI) as the best location for build the residential city on it. 
Second: to benefit from future projects for all public and private sectors when dealing with similar investments in order to achieve better feasibility in investing money.

\section{Review of Reference:-}

1. The study of (Jaewook, L \& et al., 2010). The researchers have applied a model that combines blurry target programming and hierarchical analysis, which aimed to select the best weapons system in South Korea among six military systems based on three criteria to achieve the goal of AHP (6).

2. can be used to formulate a quantitative model according to the hierarchical analysis process in the General Company for Iraqi Ports using the hierarchical analysis process to achieve the general objective of optimal distribution of public and private sector port systems, two main objectives were supported to reach one of the alternatives, which are based on four levels of basic and sub-criteria (2).

3. The study of (Sedzro, K. \& et al., 2012) the researchers have applied the model of objectives programming with the process of hierarchical analysis of the distribution of assets in the establishment of an investment portfolio taking into account market conditions and prioritize investors, and the main purpose of the use of AHP is the proper allocation of assets based on basic criteria and sub-criteria to achieve the objective of three alternatives (9).

4. The study of (Samagia \& et al., 2013) which is aimed at identifying the most important potential risks in the projects of the high-tech company for textile industries in Aleppo using the hierarchical analysis process and determining the best strategies to confront them through four criteria and four alternatives (7).

5. The study of (Bhargava, AK \& et al., 1994) the researchers in India have used the method of blurry programming with the process of hierarchical analysis in the production of pastries; the main purpose of the use of AHP is to determine the weights and their order in the target function in the model of blurry targets (4).

6. The study of (Abu Watfa, 2014) which is aimed to prioritizing the industrial sector in Palestine for achieving sustainable development among the nine alternatives based on fifteen criteria to choose between alternatives (1).

\section{Throughout the extrapolating these studies referred to above, we note that our study is different in two} fundamental points:-

The first: that our study applied for the first time in investment projects carried out by the Iraqi Investment Authority for assessing the selection of one of the sites approved by the Commission to create a residential city of more than one hundred thousand housing units with all services; where the organization invested funds worth close amount ten billion dollars Without relying on the scientific methods that contribute to the fortification and decisiveness of the decision of weakness and imbalance may be considered a serious adventure that could lead to the failure of the project or reduce the feasibility, especially as the project contributes to the treatment of one of the biggest crises suffered by the Iraqi citizen, Of housing, in addition to the many on the creation of this project that made those who support it in front of a big challenge; especially objections and while, Iraq is going through a critical economic and security crisis does not allow the error or failure in such projects.

Second: that our study is an evaluation study of decisions that have been taken by decision makers in the Iraqi government. The overall goal is to highlight upon the importance of decision-making according to scientific methods, the most important of which is the process of hierarchical analysis in selecting the best site among several sites.

\section{The Theoretical Aspect.}

The concept of hierarchical analysis process:-

The process of hierarchical analysis is considered one of the most important methods used in multi-criteria decision making, as it had proved effective and successful in finding solutions to complex problems. This theory was discovered and developed by Professor Thomas L. Saaty, who was born in Iraq- Mosul in 1926, who is one of the scientists specialized in mathematics filed, has written more than thirty books, has contributed to many fields of scientific research, and became one of the most prevalent theories in World in multi- criteria analysis and decisionmaking " (1).

The (AHP) method is the process of specific numerical points to order each an alternative by depending on the quantity of contributes for the achievement of the criteria of the decision maker. The method of hierarchical analytic is called being Consisting of several levels.Al-Saaty has defined it in 1980 as "an integrated framework that combines between an objective and non-objective criteria and the dual comparative are based on a relative scale." (2) 
While Domonsk has defined it as "as a method to support the decision-making process through selecting the best alternative among the alternatives is available on a group which it is a variety of criteria". (Davidsson\&et al,2004) Agrees with that, he has defined as a "mathematical method for evaluating a range of alternatives based on a group is overlapped from criteria" (8).

(Saaty) is once again for giving a new define it as a " Theory of building indicators using duel of comparisons that support the opinion of experts and decision makers within a defined scale" (7).

Steps of the process of hierarchical analytic:-

1. Define the problem and deter mine the type of knowledge required.

2. Building the hierarchy form for the decision-making: where in the pyramid's general goal hence, we would have put the criteria which is chosen in alternatives' context and at the bottom of the pyramid we have put the alternatives to comparative required (7).

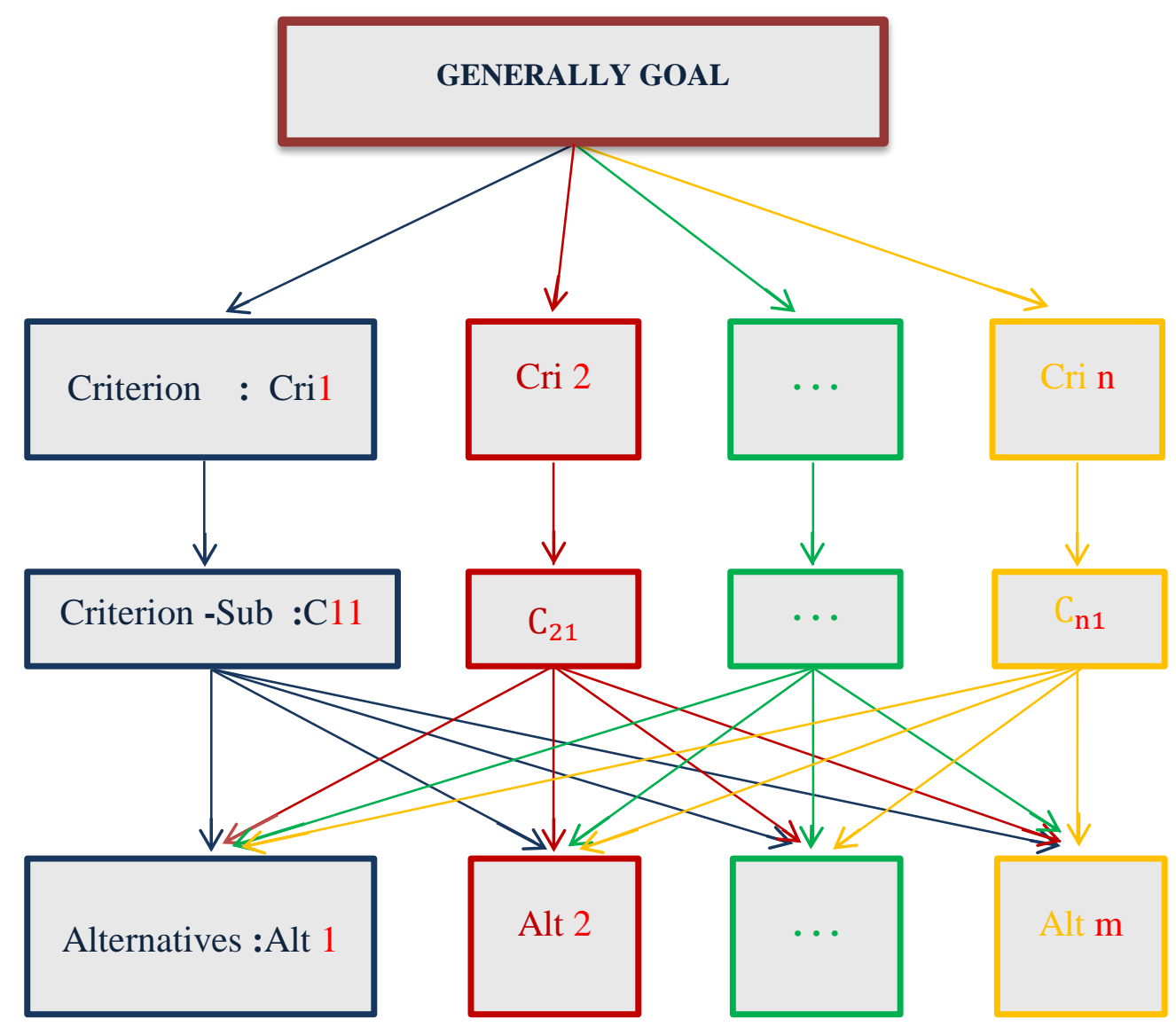

3. Building the binary comparison matrix of the main criteria and the set of alternatives within each criterion:

Binary comparisons are a numerical relationship between two alternatives or two criteria belonging to the problem being investigated. In highlight that, the importance of an element is determined by comparison to another element (7) . It can be expressed in the following matrix A:

Table(1):-

\begin{tabular}{|l|l|l|l|}
\hline$\frac{W 1}{W 1}$ & $\frac{W 1}{W 2}$ & $\cdots$ & $\frac{W 1}{W n}$ \\
\hline$\frac{W 2}{W 1}$ & $\frac{W 2}{W 2}$ & $\cdots$ & $\frac{W 2}{W n}$ \\
$=$
\end{tabular}

$=$\begin{tabular}{|l|l|l|l|}
\hline$a_{11}$ & $a_{12}$ & $\cdots$ & $a_{1 n}$ \\
\hline$a_{21}$ & $a_{22}$ & $\cdots$ & $a_{2 n}$ \\
\hline
\end{tabular}

\begin{tabular}{|l|l|l|l|}
\hline 1 & $a_{12}$ & $\cdots$ & $a_{1 n}$ \\
\hline$\frac{1}{a_{12}}$ & 1 & $\cdots$ & $a_{2 n}$ \\
\hline
\end{tabular}




\begin{tabular}{c|c|c|c|c|}
\hline $\mathrm{A}=$ & $:$ & $:$ & $:$ \\
\hline$\frac{W n}{W 1}$ & $\frac{W n}{W 2}$ & $\cdots$ & $\frac{W n}{W n}$ \\
\hline
\end{tabular}
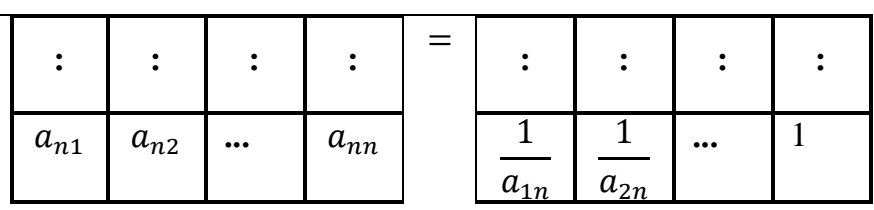

The following is a table of Al-Saaty's measures for determining the levels of relative significance of all elements of comparison (9):

Table (2):-

\begin{tabular}{|c|c|c|}
\hline Clarification & the definition & Scope of Significant \\
\hline $\begin{array}{c}\text { Both activities have contributed in the same amount } \\
\text { of significance }\end{array}$ & Are equally in significant & 1 \\
\hline Prefer a little more activity by a small degree & Medium significance & 3 \\
\hline $\begin{array}{c}\text { Experience and appreciation strongly favor activity } \\
\text { on the other }\end{array}$ & Great significance & 5 \\
\hline Activity is preferred to the other very much & Very significant & 9 \\
\hline Activity preferably on the other grade class & Of utmost significance & 7 \\
\hline
\end{tabular}

\section{Derivation of Normalized Matrix and prioritization:-}

Collecting the value of elements of each column in the binary comparison matrix, and divide each element in the binary comparison matrix on the sum of the column in which is contented it,(3) it possibility that by represented in the $\mathrm{N}$ matrix .

Table (3):-

\begin{tabular}{|c|c|c|c|c|c|}
\hline \multirow{6}{*}{$\mathrm{N}=$} & $\begin{array}{l}\text { Criteria or Goal } \\
\text { Goal or Criteria }\end{array}$ & $\begin{array}{c}\text { Cri } 1 \\
\text { OR } \\
\text { G1 }\end{array}$ & $\begin{array}{c}\text { Cri2 } \\
\text { OR } \\
\text { G2 }\end{array}$ & $\begin{array}{c}\text { Cri i } \\
\text { OR } \\
\text { Gi }\end{array}$ & $\begin{array}{c}\text { Cri n } \\
\text { OR } \\
\text { Gn }\end{array}$ \\
\hline & G1 OR C1 & $a_{11}$ & $a_{12}$ & $\ldots$ & $a_{1 n}$ \\
\hline & G2 OR C2 & $a_{21}$ & $a_{22}$ & $\ldots$ & $a_{2 n}$ \\
\hline & $\mathrm{Gj}$ OR Ci & : & : & : & : \\
\hline & Gn OR Cn & $a_{n 1}$ & $a_{n 2}$ & $\cdots$ & $a_{n n}$ \\
\hline & Sum & Crilor G1 $\sum$ & $\ldots$ & $\ldots$ & Crilor G1 $\sum$ \\
\hline
\end{tabular}

To find the average of the rows, collecting the values of elements of each row in the modified binary comparison matrix $\mathrm{N}$ and divide them by the total number of those elements, (3) possibility that by represented in the following table:

Table (4):-

\begin{tabular}{|c|c|c|c|c|c|c|c|}
\hline \multirow{5}{*}{$\mathrm{N}=$} & $\begin{array}{l}\text { Crei or G } \\
\text { G or Crei }\end{array}$ & $\begin{array}{l}\text { Cri } 1 \\
\text { OR } \\
\text { G1 }\end{array}$ & $\begin{array}{l}\text { Cri } 2 \\
\text { OR } \\
\text { G2 }\end{array}$ & $\begin{array}{l}\text { Cri } 3 \\
\text { OR } \\
\text { G3 }\end{array}$ & $\begin{array}{l}\text { Cri i } \\
\text { OR } \\
\text { Gi }\end{array}$ & $\begin{array}{l}\text { Crin } \\
\text { OR } \\
\text { G1 }\end{array}$ & $\begin{array}{l}\text { An verage } \\
\text { of the rows }\end{array}$ \\
\hline & G1 OR C1 & $a_{11}$ & $a_{12}$ & $a_{13}$ & $\ldots$ & $a_{1 n}$ & W1 \\
\hline & G2 OR C2 & $a_{21}$ & $a_{22}$ & $a_{23}$ & $\ldots$ & $a_{2 n}$ & W2 \\
\hline & Gj OR Ci & : & $:$ & : & $:$ & $:$ & $:$ \\
\hline & Gn OR Cn & $a_{n 1}$ & $a_{n 2}$ & $a_{n 3}$ & $\ldots$ & $a_{n n}$ & Wn \\
\hline
\end{tabular}

\section{Measuring of Stability or Consistency (Non-Contradiction)}

The prioritization of a binary comparison requires that the provisions are consistent. Whereas, the (AHP) provides a measure of the consistency of the binary comparison rules through be calculating of consistency ratio, which is designed before whereas, that the values are increasing than 0.10 value which indicates to the rules are inconsistent and in the case if it is equal the ratio above or it was a lower than a ratio from it as result, which is express an acceptable level of consistency in binary comparisons(3). 
The Possibility be estimated consistency rate of alternatives or criteria according to the following steps:

a. Calculating the intrinsic vector value: be calculating the intrinsic value of the vector thro ugh multiply the binary comparison matrix $\mathrm{A}$ in the average row column $\mathrm{W}(3)$

Table (5)

B.

$\mathrm{W} \times \mathrm{A}==$ Eigen Value

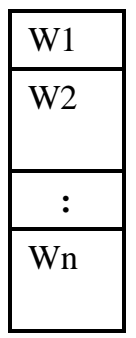

\begin{tabular}{|c|c|l|c|}
\hline 1 & $a_{12}$ & $\ldots$ & $a_{1 n}$ \\
\hline$\frac{1}{a_{12}}$ & 1 & $\ldots$ & $a_{2 n}$ \\
\hline$:$ & $:$ & $:$ & $:$ \\
\hline$\frac{1}{a_{1 n}}$ & $\frac{1}{a_{2 n}}$ & $\ldots$ & 1 \\
\hline
\end{tabular}

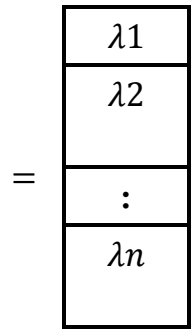

Calculate the maximum arithmetic mean: It can be calculated from the following relationship (5):

$\lambda \max =\frac{1}{n} \sum_{i=1}^{n} \frac{A w}{W}$

C. Calculating the value of stability index: The stability index value is calculated as the comparison matrix according to the following (4):

$\mathbf{C I}=\frac{\max \lambda-\mathbf{n}}{\mathbf{n}-\mathbf{1}}$

D. Calculating of homogeneity ratio value: be calculating the homogeneity value of the comparison matrix as follows (4):

$C R=\frac{\text { CI }}{\text { RI }}$

Where RI: represents the indicator of random consistency for the random binary comparison matrix; hence, to be values of RI based on the number of items compared (6) according to table follows:

Table (6):- clarifies the values of indicator of random consistency

\begin{tabular}{|c|c|c|c|c|c|c|c|c|c|}
\hline 9 & 8 & 7 & 6 & 5 & 4 & 3 & 2 & 1 & $\mathrm{~N}$ \\
\hline 1.45 & 1.41 & 1.32 & 1.24 & 1.12 & 0.90 & 0.58 & 0 & 0 & Random Indicator \\
\hline
\end{tabular}

C. The Combining between priorities of the criteria and the priorities of each an alternative decision: We obtain the general priority of each an alternative decision by collecting the priority of the priority in the priority of its alternative decisions, and then, we should be calculated the general priority for choosing each an alternative as a separately for getting the final decision, in order of priority values, in order to have got the final alternatives to a decision (3).

Applied Research Frame:-

This aspect deals with the model of the hierarchical analytic process to determine the better alternative. Whereas, will take the selection of the national investment organization for the location which it has adopted as the best location to build the city out of three alternative locations are based on several criteria.

\section{Determine the relative importance of criteria:}

The guidance of measurement by techniques presented in the theoretical aspect, the following criteria had chosen: (Security environment is suitable for investment, proximity to the most densely populated population, proximity to water sources, clearance of land from any related) in order to determine the best location and then evaluate it in light of the selection of the National Investment Organization. In the light of the results is produced by questionnaire forms of amount (10) form, which were distributed to experts and specialists in the Authority and abroad to express an opinion on the importance of each criterion for other criteria, the number of forms obtained (7) form, means range $70 \%$ of the total forms. 


\section{Required Elements by (AHP):}

The Building requirements of the hierarchical model for study according to AHP theory determining the following elements:

A. Determining the overall objective of the hierarchical structure: Based on the theoretical aspect, the study had adopted ("choosing the best location") as the overall aim of the hierarchical structure.

B. The Criteria has used in the process of comparison between alternatives: The study is adopted four criteria as we will be referred to it in 4.3 (Prioritization using AHP).

C. Available alternatives: The available alternatives were determined according to the overall objective of the hierarchical structure in three alternatives: (Basmaya city Location, Husseiniya location, Taji location).

D.

Based on this, the study model can be constructed according to the requirements of Shah as shown in Figure (2) below:

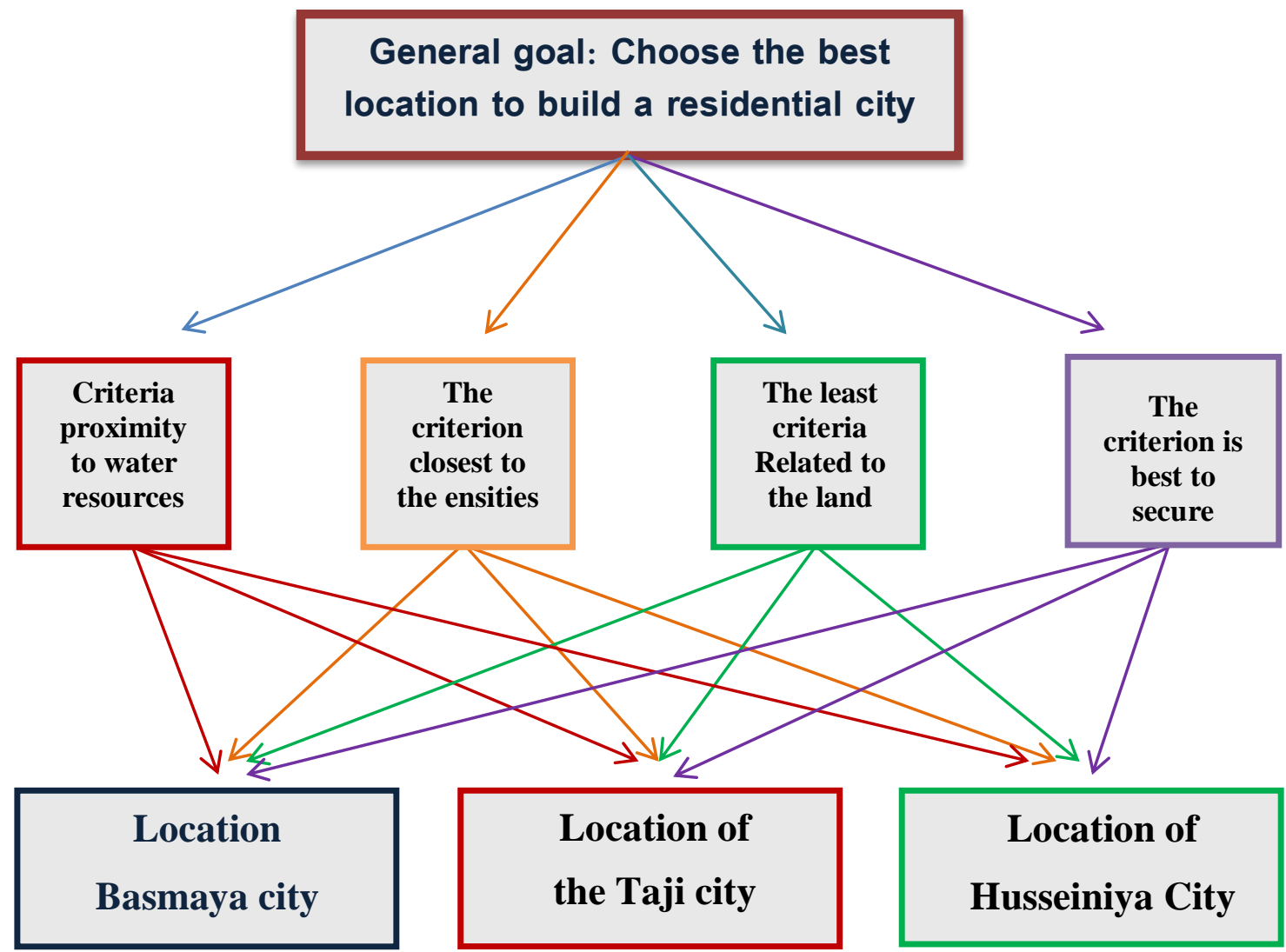

3. Prepare priorities by using AHP:

The priorities should be identified in the problem of evaluating the chosen location of the residential city are:

A. The location of the three cities in light of the criteria of the location is the best secure.

B. The location of the three cities is in light of the criteria of the location nearest to population densities.

C. The locations of the three cities in light of the criteria of the best location whereas related to land.

D. The locations of the three cities are in the light of the criteria location nearest to water resources.

E. The four criteria in light of the general goal.

The first criterion: The criterion is best to secure:-

1. Binary Comparison Matrix: The binary comparison matrix is placed in the three locations in the light of the criteria most secure location as in the following table:

Table (7):

\begin{tabular}{|c|c|c|c|}
\hline Basmaya & Taji & Husseiniya & Security criterion \\
\hline $1 / 4$ & 5 & 1 & Husseiniya \\
\hline $1 / 8$ & 1 & $1 / 5$ & Taji \\
\hline
\end{tabular}




\begin{tabular}{|c|c|c|c|}
\hline 1 & 8 & 4 & Basmaya \\
\hline 1.375 & 14 & 5.2 & Total \\
\hline
\end{tabular}

\section{Derivation of the modified matrix:-}

Table (8):-

\begin{tabular}{|c|c|c|c|c|}
\hline Average rows & Basmaya & Taji & Husseiniya & Security criterion \\
\hline 0.2435 & 0.1817 & 0.3570 & 0.1922 & $\mathrm{Al}-\mathrm{Husseiniya}$ \\
\hline 0.0669 & 0.0908 & 0.0713 & 0.0385 & $\mathrm{Al}-\mathrm{Taji}$ \\
\hline 0.6891 & 0.7273 & 0.5713 & 0.7691 & Basmaya \\
\hline
\end{tabular}

The results of Analysis: This matrix protective us the relative priorities for the three cities in the light on the criterion of the best location security, and when looking at the matrix, we find that the best location is the city of Basmaya priority (0.6891) followed by the city of Husseiniya priority of (0.2435) Followed, Taji with a priority of (0.0669); this indicates that the location of the city of Basmaya is the best location in terms of the criterion of the best security location.

Measuring the consistency ratio to ensure that the results are accepted, we find:

\section{A. Self-vector value:-}

Table (9):-

\begin{tabular}{|c|c|c|c|c|}
\hline Self-vector & Basmaya & Taji & Husseiniya & The Security criteria \\
\hline 0.7503 & 0.1723 & 0.3345 & 0.2435 & Husseiniya \\
\hline 0.2016 & 0.0860 & 0.0669 & 0.0487 & Taji \\
\hline 2.1983 & 0.6891 & 0.5352 & 0.974 & Basmaya \\
\hline
\end{tabular}

B. Maximum arithmetic mean:

$\lambda \max =\frac{1}{n} \sum_{i=1}^{n} \frac{A W}{W}=3.09496$

C. The Value of stability index: The stability index value is calculated as the comparison matrix according to the following:

$\mathrm{CI}=\frac{\max \lambda-\mathbf{n}}{\mathrm{n}-\mathbf{1}}=\mathbf{0 . 0 4 7 5}$
D. Calculating of homogeneity ratio value:
$C R=\frac{\text { II }}{\text { RI }}=0.0819$

Including the value of $(C R=0.0819)$ and the value of $(C I=0.0475)$ were less than $(0.1)$, as a result, the priority ratios of the first criterion within the acceptable limit according to the Saaty's theory.

Within the same steps, other priorities can be found as shown in the following table

Table (10):-

\begin{tabular}{|c|c|c|}
\hline Results & Priorities & Criterion \\
\hline \multirow{3}{*}{$\begin{array}{l}\max \lambda=3.0764 \\
C I=0.0383 \\
C R=0.0660\end{array}$} & 0.1549 & \multirow{3}{*}{$\begin{array}{l}\text { Second criterion: the criterion of } \\
\text { location nearest to Population } \\
\text { densities }\end{array}$} \\
\hline & 0.0683 & \\
\hline & 0.7765 & \\
\hline \multirow{3}{*}{$\begin{array}{l}\max \lambda=3.08123 \\
C I=0.0405 \\
C R=0.0700\end{array}$} & 0.2344 & \multirow{3}{*}{$\begin{array}{l}\text { The third criterion: the criterion of } \\
\text { the best location whereas related to } \\
\text { land. }\end{array}$} \\
\hline & 0.0778 & \\
\hline & 0.6876 & \\
\hline \multirow{3}{*}{$\begin{array}{l}\max \lambda=3.0542 \\
C I=0.0271 \\
C R=0.0467\end{array}$} & 0.2112 & \multirow{3}{*}{$\begin{array}{l}\text { The fourth Criterion : The criterion } \\
\text { of location nearest to water } \\
\text { resources }\end{array}$} \\
\hline & 0.6551 & \\
\hline & 0.1335 & \\
\hline
\end{tabular}

Including the ratio of homogeneity and stability value of the binary comparison matrix of the four criteria was less than (0.1), the priority ratios are within the acceptable limit according to Saaty's theory.

E. Arrangements of priority factors: we should prioritize the following table for each of the location's greatest secure criterion, the best location whereas relates of land and the best location in terms of 
proximity to Population densities and the location of the best in terms of nearness to water resources in the problem of evaluating the choice of the best city location between the three locations as follows:

Table (11):- Priority factors for all criteria are listed in the following table:

\begin{tabular}{|c|c|c|c|c|}
\hline Criteria 4 & Criteria 3 & Criteria 2 & Criteria 1 & Criteria Goal \\
\hline 0.2112 & 0.2344 & 0.1549 & 0.2435 & Alt 1 \\
\hline 0.6551 & 0.0778 & 0.0683 & 0.0669 & Alt 2 \\
\hline 0.1335 & 0.6876 & 0.7765 & 0.6891 & Alt 3 \\
\hline
\end{tabular}

Observing when we conducted the binary comparisons of the three positions in light of the four criteria, we did not get a better location than any other criteria, Where the results showed that the location of Basmaya is the best in terms of security criterion and related of land and Population density, But the Taji's location is the best in terms of nearness to water resources.

\section{The Binary comparisons of the four criterions used in selecting the optimal alternative:-}

We will work on finding a matrix of binary comparisons for determining the priorities of the four criteria in light of their importance in contributing toward to the general goal. Whereas the comparative matrices (binary) of the targets will be prepared based on the hierarchical analysis using the relative weights of the objectives obtained from the distribution of the questionnaire and as follows:

Table (12):- Binary Comparison Matrix

\begin{tabular}{|c|c|c|c|c|}
\hline Criteria 4 & Criteria 3 & Criteria 2 & Criteria 1 & Goal i \\
\hline 4 & 3 & 2 & 1 & Criteria 1 \\
\hline 3 & 2 & 1 & $1 / 2$ & Criteria 2 \\
\hline 1 & 1 & $1 / 2$ & $1 / 3$ & Criteria 3 \\
\hline 1 & 1 & $1 / 3$ & $1 / 4$ & Criteria 4 \\
\hline 9 & 7 & 4.8332 & 2.0832 & Total \\
\hline
\end{tabular}

Table (13):- Table of average rows

\begin{tabular}{|c|c|c|c|c|c|}
\hline Average & Criteria 4 & Criteria 3 & Criteria 2 & Criteria 1 & Goal i \\
\hline 0.4417 & 0.4443 & 0.4286 & 0.4137 & 0.4800 & Criteria 1 \\
\hline 0.2664 & 0.3332 & 0.2856 & 0.2068 & 0.2400 & Criteria 2 \\
\hline 0.1294 & 0.1110 & 0.1429 & 0.1035 & 0.1600 & Criteria 3 \\
\hline 0.1106 & 0.1110 & 0.1429 & 0.0690 & 0.1200 & Criteria 4 \\
\hline
\end{tabular}

Analysis of the results of general goal: The matrix presents us the relative priorities of the criteria set in the light of the general goal, when we look at them, the best criterion is the most safe location criterion with a priority of (0.4417), followed by the reputable and competitive criterion in the foreign product competition with a priority of $(0.3276)$ and followed by the priority of the rest of the standards.

The rate of consistency of the general target can be estimated

Table (14):- Self - vector matrix

\begin{tabular}{|c|c|c|c|c|c|}
\hline Self - vector & Criteria 4 & Criteria 3 & Criteria 2 & Criteria 1 & Goal i \\
\hline 1.8052 & 0.4424 & 0.3883 & 0.5328 & 0.4417 & Criteria 1 \\
\hline 1.0779 & 0.3318 & 0.2588 & 0.2664 & 0.2209 & Criteria 2 \\
\hline 0.5203 & 0.1106 & 0.1294 & 0.1332 & 0.1471 & Criteria 3 \\
\hline 0.4391 & 0.1106 & 0.1294 & 0.0888 & 0.1103 & Criteria 4 \\
\hline
\end{tabular}

The results can be summarized in the following table

Table (15):-

\begin{tabular}{|l|c|c|}
\hline \multicolumn{1}{|c|}{ results The } & \multicolumn{2}{c|}{ The priority of the four criteria in light of the general goal } \\
\hline $\max \lambda=4.0310$ & 0.4417 & The first criterion \\
$C I=0.0102$ & 0.2664 & The second criterion \\
\hline
\end{tabular}


$C R=0.0115$

0.1294

0.1106

The third criterion

The fourth criterion

Including the value of $(\mathrm{CR}=0.0 .0115))$ and the value of $(\mathrm{CI}=0.0103)$ of the binary comparison matrix was less than $(0.1)$, then the priority ratios are within the acceptable range according to Saaty's theory.

Table (16):- Priorities of the four criteria in light of the general objective

\begin{tabular}{|c|c|}
\hline priority & Criterion \\
\hline 0.4417 & The most secure location \\
\hline 0.2664 & The location is the best in terms of lack of belongings in land \\
\hline 0.1294 & The best location in terms of proximity to populations densities \\
\hline 0.1106 & The location is the best in terms of nearest to water resources \\
\hline
\end{tabular}

The Combine priorities of criterions and priorities for each alternative decision:-

In this section, we will explain how to combine the priorities of the criteria and the priorities of each alternative decision for each criterion to determine the general standing of the priority of alternatives to the decision and thence, evaluating the alternative adopted by the National Investment Authority.

We will obtain the general priority of each alternative decision by combining the priority of the criteria in Table (16) in the priority of its alternative decision in Table (11). Hence, We calculate the general priority of selecting each location is separate to get the final decision for AHP. In order of priority values, we have obtained the final order of the hierarchical analysis of decision alternatives and as in the following table:

Table (17):-

\begin{tabular}{|c|c|}
\hline priority & Alternative \\
\hline 0.2024 & Location of Husseiniya City \\
\hline 0.1303 & Location of Taji city \\
\hline 0.4187 & Location Basmaya city \\
\hline
\end{tabular}

These final results regarding the selection of a location from among several locations where the location of the city of Basmaya in light of the criteria set was the preferred location according to the AHP so that the choice adopted by the Investment Authority is true.

\section{Conclusions:-}

1. The National Investment Authority has not adopted scientific methods of differentiation between alternatives such as modern quantitative methods in decision-making, Including the mothed of AHP.

2. The efficiency of the hierarchical analysis model in selecting locations or determining their priorities.

3. We conclude from the results of the first part when are conducting the binary comparisons of the three locations in light of the four criterions, we did not get a better location than any other in terms of all standards; therefore, we did not make a final decision to determine the best location.

4. The final results are concerning in selection of a location from among several locations indicated that the location of Basmaya city in light of the criteria set was the preferred location according to the process of hierarchical analysis so that the choice adopted by the investment Authority is correct.

5. The use method of AHP provides a flexible way and easy to understand for selecting alternatives and prioritizing and allows the management to make the decision of objectively and collectively.

\section{Recommendations:-}

1. The necessity to give priority in any investment plan similar to scientific methods in order to be a process of choosing alternatives more useful in achieving the goals.

2. The necessity is using quantitative methods in making important decisions such as AHP method to avoid the risk of investing large sums to create projects that may be of little or no use for the purpose of investment, in order for the decision to be taken in a sound scientific manner.

3. Be Training the staff of decision-making of the National Investment Authority or in the public and private sectors and Definition of a theory of hierarchical analysis for them. 


\section{References:-}

1. Abu Watfa, Hossam Ahmed, 2014, Use of the Hierarchical Analysis Process in Prioritizing the Industrial Sector in Palestine for Sustainable Development, a thesis submitted to the Faculty of Commerce / Islamic University Gaza - for a Master's degree in Economics of Development.

2. Al-Rashed, Ahmed Ali Ahmed, 2011, "Evaluation of Opportunities for Private Sector Participation in the Completion and Development of the Operations of the Iraqi Ports (AHP) Using the Hierarchical Analysis Process Field Study in the General Company for Iraqi Ports", Journal of Economic Sciences, Volume 28, Volume VII: 112-158.

3. Anderson, David, Sweeney, Dennis Sweeney, Williams and Thomas Williams, 2006, "Quantitative Methods in Management," trans by Mohammed Tawfiq Al-Balkini, Riyadh, Dar Al-Marikh Publishing.

4. Bhargava. A.K, Singh. S.R\& Bansal. D,2014, " A Fuzzy Goal Programming Model for Bakery Production", International Journal of Computer \& Mathematical Sciences IJCMS ISSN 2347 - 8527 Volume 3, Issue 4 June 2014

5. Kolios.A, Mytilinou .V , Lozano-Minguez E \& Salonitis K ,2016," A Comparative Study of Multiple-Criteria Decision-Making Methods under Stochastic Inputs",Energies 2016, 9, 566; doi:10.3390/en9070566 http://www.mdpi.com/journal/energies

6. Lee.J, Kang.S-H, Rosenberger.J\& Seoung Bum Kim .S.B,2010," A hybrid approach of goal programming for weapon systems selection", Computers \& Industrial Engineering 58 (2010) 521-527

7. Saaty.T,2008," Decision making with the analytic hierarchy process"Int. J. Services Sciences, Vol. 1, No. $1,200883$.

8. Smagia,Watata and Bushra andBatool, 2014, "Risk Management in Textile Industries in Aleppo using AHP", Al-Quds Open University Journal for Research and Studies, 34th Issue: 368-341.

9. Sedzro.K, Marouane.A\& Assogbavi.T,2012," Analytical Hierarchy Process and Goal Programming Approach for Asset Allocation",Journal of Mathematical Finance, 2012, 2, 96104 